TECHNICAL NOTE

\title{
A novel procedure to measure shrinkage-free tree-rings from very large wood samples combining photogrammetry, high-resolution image processing, and GIS tools
}

\author{
Nicolas Latte ${ }^{\mathrm{a}, *}$, Hans Beeckman ${ }^{\mathrm{b}}$, Sébastien Bauwens ${ }^{\mathrm{a}}$, \\ Stéphanie Bonnet ${ }^{\mathrm{a}}$, Philippe Lejeune ${ }^{\mathrm{a}}$ \\ ${ }^{a}$ Forest Resources Management, University of Liège, Gembloux Agro-Bio Tech, Passage des Déportés 2, 5030 Gembloux, Belgium \\ ${ }^{\mathrm{b}}$ Service of Wood Biology, Royal Museum for Central Africa, Leuvensesteenweg 13, 3080 Tervuren, Belgium
}

\section{A R T I C L E I N F O}

\section{Article history:}

Received 28 October 2014

Accepted 13 March 2015

\section{Keywords:}

Dendrochronology

Tropical tree species

Semi-automatic ring measurement

VBA application

Stem disk analysis

Geographic information systems (GIS)

\begin{abstract}
A B S T R A C T
We present a new procedure for wood sampling and tree-ring measurement that can be used for dendrochronological investigation on very large trees, specifically adapted for tropical rainforest species. This procedure takes advantage of the technological developments in computing, image processing, and geographic information systems (GIS) to overcome the technical limitations of the currently used methods. Two types of wood samples can be used (stem disks and/or bars) depending on tree diameter, and the difficulty of ring delineation and crossdating. Bars are an effective compromise between cores and disks. We developed an application combining several programs (Excel, R, ArcGIS, and MapWinGIS) in the Windows operating system for semi-automatic measurement of tree-rings from high-resolution images of the sanded cross-section. Using an innovative method to reverse the wood shrinkage resulting from the drying process, tree-ring measurement can be performed on shrinkage-free images, thus referring to the actual growth of the tree.
\end{abstract}

(C) 2015 Elsevier GmbH. All rights reserved.

\section{Introduction}

Tree-ring analysis and dendrochronology rely on the precise measurement of a large number of accurately dated rings. Measurements are typically conducted semi-automatically, with a stereomicroscope and a line table (e.g., LinTab and Velmex), or through digitized images using specific analysis software (overview available at http://web.utk.edu/ grissino/software.htm). However, both approaches present limitations for very large trees and when coring routine is not feasible due to high wood density, very irregular stem form or other technical problems. On the one hand, direct measurement of heavy and bulky disks is a challenging task; e.g., a disk $1 \mathrm{~m}$ in diameter with a thickness of $0.15 \mathrm{~m}$ weighs approximately $100 \mathrm{~kg}$. On the other hand, the currently available image analysis softwares for tree-ring research routine are not capable of handling large image files; e.g., the image file of a 1 -m-diameter tree disk at 1200 dots per inch (dpi) resolution in the tagged image file (.tif) format occupies approximately $24 \mathrm{~Gb}$

\footnotetext{
* Corresponding author. Tel.: +32 81622 515; fax: +32 81622301 .

E-mail address: nicolas.latte@ulg.ac.be (N. Latte).
}

of disk space. These technical limitations are a major hindrance toward dendrochronological investigations, in particular in tropical rainforests. In comparison with temperate zones, tree-rings are often anatomically less distinct and there exists some uncertainty regarding their annual nature (Rozendaal and Zuidema, 2011), necessitating the observation of wood anatomical structure and measurements at higher resolution. In most cases, automatic detection of ring boundaries is not possible for tropical tree species compelling manual detection by experienced eyes (Worbes, 2002).

Disk stem cross-sections contain a lot of information relevant for growth analysis, reconstruction of environmental influences, and wood quality evaluation. Wood samples are typically exposed to dimensional shrinkages during the drying process. Radial and tangential shrinkages from the fibre saturation point to a moisture content of $12-15 \%$ can amount to up to about $5 \%$ and $10 \%$, respectively (Kukachka, 1970; Wagenführ, 1996). Considering a disk radius of $50 \mathrm{~cm}$, these shrinkages correspond to absolute maximum values of 2.5 and $5 \mathrm{~cm}$, respectively. Furthermore, these shrinkages can vary considerably with respect to species, growing conditions, and between and within the wood samples (juvenile/mature wood, duramen to sapwood transition, defects, etc.). However, shrinkage is usually not taken into consideration during 


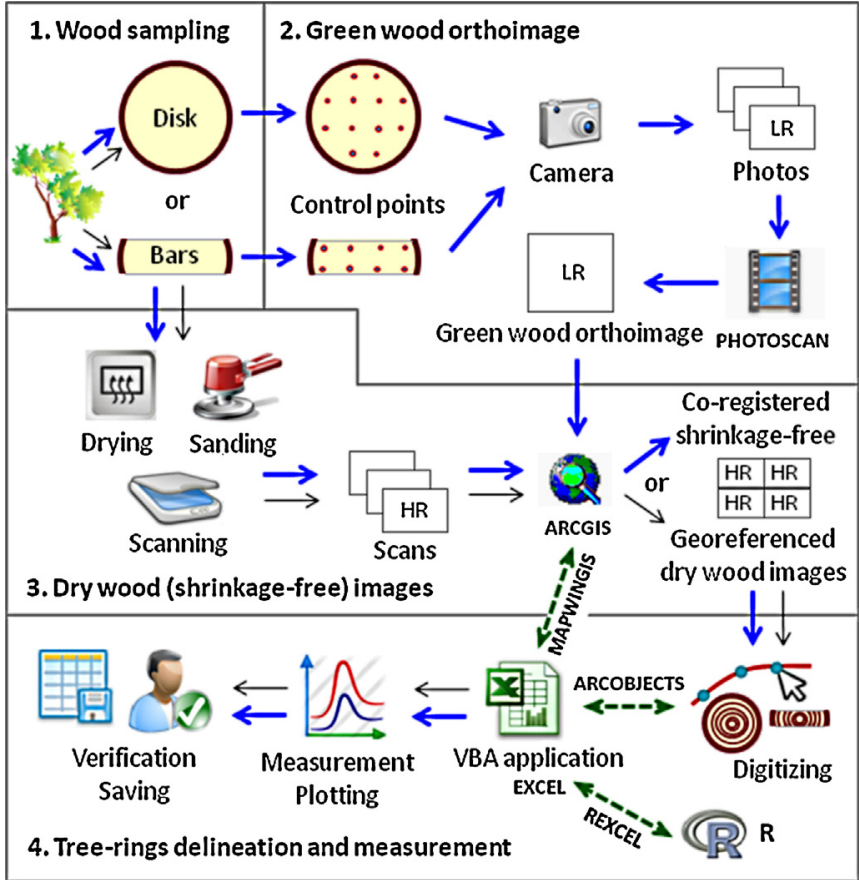

Fig. 1. Synthetic flowchart of the complete procedure (phases 1-4; thick arrows) and simplified procedure (phases: 1, 3 and 4; thin arrows). LR: low resolution. HR: high resolution. VBA: visual basic for applications.

tree-ring studies, which are mainly focused on the year-to-year growth variability. In view of the rising dendrochronology potential of tropical forests (Gebrekirstos et al., 2014; Groenendijk et al., 2014), forestry research could benefit significantly from a detailed method for determining the shrinkage-free growth pattern and variation during the complete lifespan of a tree.

In this study, we present a new procedure for wood sampling and ring measurement that can be applied to very large wood samples. The procedure integrates recent technological developments (64-bit operating system, high capacity for data storage, and novel image processing software) in order to produce high-resolution images, and subsequently to manually delineate and automatically measure tree rings from these images. To this end, several wellknown programs were combined in Windows 7 (64-bit version): Photoscan (AgiSoft LLC), ArcGIS 9.3 (geographic information system [GIS]: ArcMap and ArcObjects, ESRI), Excel 2007 (Microsoft Office), and R (R Core Team, 2014). Tree-ring measurement can be performed on shrinkage-free images, and thus, corresponds to the actual growth of the tree.

\section{Description of the procedure}

The complete procedure was divided into four phases (Fig. 1, thick arrows), and was developed for large trees of several species of African tropical rainforests, including Entandrophragma cylindricum Sprague, Erythrophleum ivorense A. Chev., Pericopsis elata (Harms) van Meeuwen, Baillonella toxisperma Pierre, and Aucoumea klaineana Pierre, but could potentially be applied to any tree species from any type of forest. A simplified version of this procedure excludes the second phase used for reversing multidirectional shrinkages (Fig. 1, thin arrows). The complete procedure is aimed toward studies focusing on unbiased growth variation and pattern (from raw values), rather than on dendrochronological investigations on climate-driven year-to-year variability (from growth indices).

\section{Phase 1: wood sampling}

One wood disk is sawed from a felled tree, preferably at a point where the stem form is the most regular, and without defects or major deformations. The disk height among samples varies from 5 to $15 \mathrm{~cm}$ depending on the tree diameter, as a compromise between the weight of the disk and the risk of cracking. At that point, two types of samples can be used (Fig. 2): (i) the disk as a single piece, or four bars of $20-\mathrm{cm}$ width $(\mathrm{A} 1, \mathrm{~A} 2, \mathrm{~B}$, and $\mathrm{C})$ sawed from the disk. Bars $A 1$ and $A 2$ include the pith, and bars $B$ and $C$ are perpendicular to the diameter A1-A2. The choice of sample type depends on several criteria, which are discussed at the end of the procedure description.

\section{Phase 2: green wood orthoimage}

Holes of 4-mm diameter are drilled into the green disk using a cordless hand drill (Fig. 2). These holes are used as control points to process images during phases 2 and 3. The distribution of control points is adapted to the type of sample: for the disk sample, these are distributed all over the cross-section following a square grid, and for the bar samples, the control points are located lengthwise, close to the edges (Fig. 2). In our experience, for accurate image processing, the distance between control points should not exceed $10 \mathrm{~cm}$ for disks and $6 \mathrm{~cm}$ for bars.

The disk with the drilled control points is cleaned up using an air gun and placed on the floor. Photos are taken from the top of the
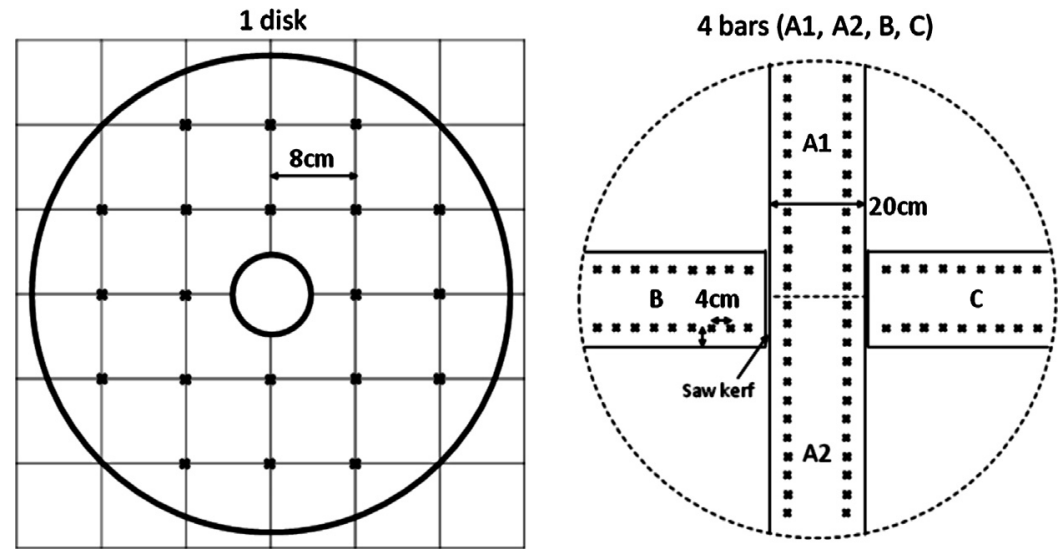

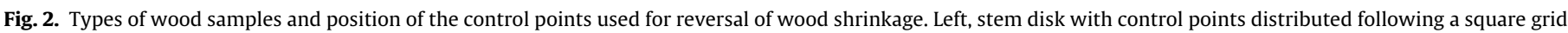
of $8 \mathrm{~cm}$. Right, four bars of $20-\mathrm{cm}$ width (A1, A2, B, and C) with control points equally spaced $(4 \mathrm{~cm})$ lengthwise. 


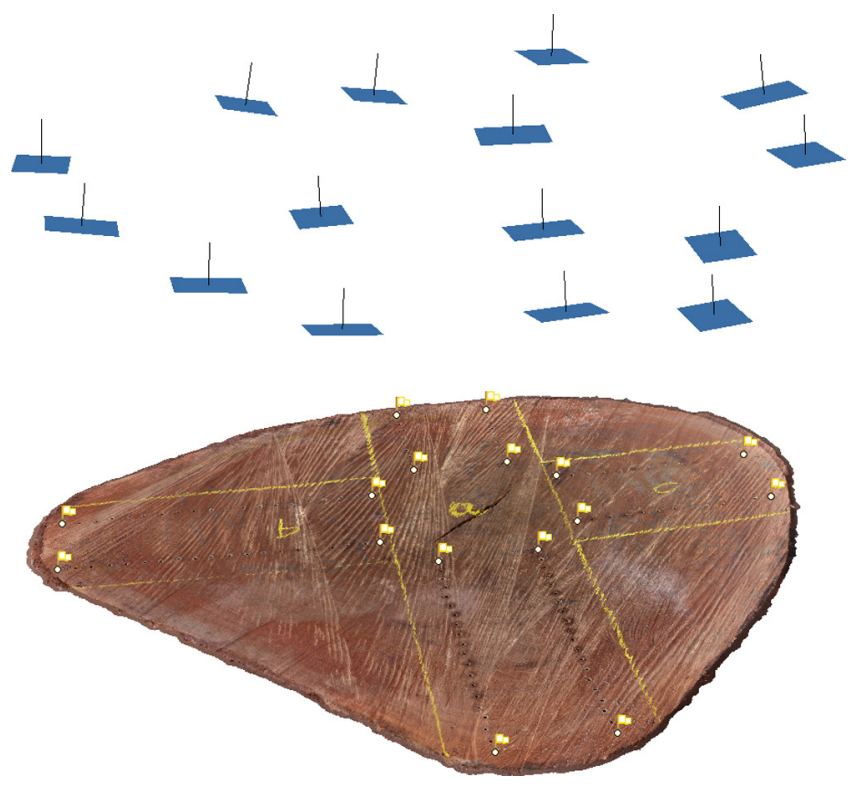

Fig. 3. Perspective view of the dense cloud points generated by Photoscan of a green disk cross-section (diameter of about $70 \mathrm{~cm}$ ). Rectangles in the upper part of the figure correspond to some of the camera positions at the time of shooting. The flags indicate the two first and two last control points of each of the four bars.

disk with an off-the-shelf camera (Canon EOS 50D; Tokyo, Japan). The overlap between the photos must be at least half in any direction. While shooting, the photographer must be standing as close to the disk as possible. Photos must be as perpendicular as possible covering the whole cross-section, with a large border to capture the disk edge. The camera can be set to automatic mode (aperture, shutter speed and ISO) but the focal length must be fixed (ideally without autofocus). Only non-blurry photos are retained.

Photos are then assembled together into a green wood orthoimage (.tif; Fig. 3) using the Photoscan software v1.0 (Agisoft; Carshalton, UK) in five steps: (i) image block alignment (structurefrom-motion); (ii) manual marking of control points, and setting up of scale bars for each pair of successive control points (accurate measurement of the distance between control points); (iii) refining camera positions and calibration, based on scale bars; (iv) multiview stereo matching resulting in a dense cloud and mesh; and (v) generation of the green wood orthoimage by mosaic blending. Although the image block orientation is in a relative coordinate system, the scaling is precisely handled using control points, and the resulting orthophotomosaic is in a metric coordinate system, which is convenient for further tree-ring measurements.

\section{Phase 3: dry wood shrinkage-free images}

Wood samples (disk or bars) are dried and sanded with grits, ranging from 40 to 400-1200, and scanned at 1200-1800 dpi using a flatbed A3 scanner (Epson Expression 10000 XL, Epson; Nagano, Japan). Depending on the dimensions of the wood sample, one or several scans are carried out with an overlapping strip of at least $3 \mathrm{~cm}$. Automatic focus is systematically operated before each scanning for improved image sharpness. In the case where the wood surface is not perfectly plane, the scanning area should be divided into several windows in order to avoid blurry effects (due to the varying distance between the scanner glass and cross-section). A homemade wood frame is used to protect the scanner from heavy wood samples.

The scans are georeferenced in a metric coordinate system in ArcMap (ArcGIS 9.3; ESRI, Redlands, CA, USA) and then stored in a geodatabase of about 3-30 Gb depending on the type and dimension of wood sample used, and the image resolution required. In the complete procedure, the scans are co-registered to produce a high-resolution shrinkage-free image of the dry wood crosssection (Fig. 1, thick arrows). The control points of the green disk orthoimage are used to reverse radial and tangential shrinkages. The co-registration is based on spline transformation, which optimizes local accuracy and maintains continuity and smoothness between the different parts of the image. The true rubber sheeting method is particularly effective when numerous control points can be defined and their positions are registered precisely (ESRI, 2014).

\section{Phase 4: tree-ring delineation and measurement}

Using ArcMap, the ring boundaries are digitized as polylines using the co-registered (complete procedure) or georeferenced (simplified procedure) dry wood images as background layers. GIS environments are optimized to handle files and datasets of large sizes, and offer numerous graphical applications (zoom in, zoom out, pan, image rotation, color stretching, etc.) that enable the display of images and digitized rings in a comfortable and efficient manner for the operator.

A specific application was developed to: (i) transform the digitized polylines into a structured layer of polygons (which are placed in a chronosequence of successive rings, from the pith to the bark), (ii) automatically measure tree-rings from the polygons, (iii) plot the resulting tree-ring series and compare them for bars, and (iv) export pre-validated measurement data into the TUCSON format. The application was written in the Visual Basic for Applications (VBA) language in a Microsoft Excel Interface (Microsoft Corporation; Redmond, WA, USA) controlling the external components ArcObjects, MapWinGIS, and R (dotted arrows, Fig. 1). ArcObjects is a set of platform-independent software components that provides the services and functionalities of ArcGIS. MapWinGIS (open source) provides the GIS and mapping functionality to any Windows forms-based application such as Excel. The link between Excel and $\mathrm{R}$ is provided by the package 'RExcel' (Baier et al., 2011). The Excel platform and all the external components are interconnected and work simultaneously on the same geodatabase, which stores all the necessary data: green and dry wood images, and polyline and polygon layers. Tree-ring width is computed by taking an average of the values of a large number of measures throughout each ring (Eq. (1)), and is thus very highly correlated with the ring area. Other statistics (standard deviation, quantiles, minimum, maximum, etc.) are also computed to characterize the overall statistical dispersion. GIS tools were already used to accurately measure ring area of dwarf shrubs (Bär et al., 2006).

$$
W_{i}=\sqrt{\frac{1}{n} \sum_{j}^{n} W_{i j}^{2}}
$$

$W_{i}(\mathrm{~mm})$ denotes the width of the ring $i, W_{i j}(\mathrm{~mm})$ denotes the perpendicular distance between the tangent of the vertex $j$ of the ring $i$, to the previous ring $(i-1)$, and $n$ denotes the number of vertices considered for the ring $i$. The vertices are generated during the digitizing process (approximately 1 every $5 \mathrm{~mm}$ ).

When using bars, four tree-ring series are computed: 2 complete series (bars A1 and A2), and 2 truncated series (bars B and C with the missing pith, Fig. 2). These series are compared to each other in ArcMap (Fig. 4), and in Excel using an interactive plot (Fig. 5). Treering series are detrended and cross-correlations between series are computed using the Dendrochronology Program library of R ('dplR' package; Bunn, 2008). 


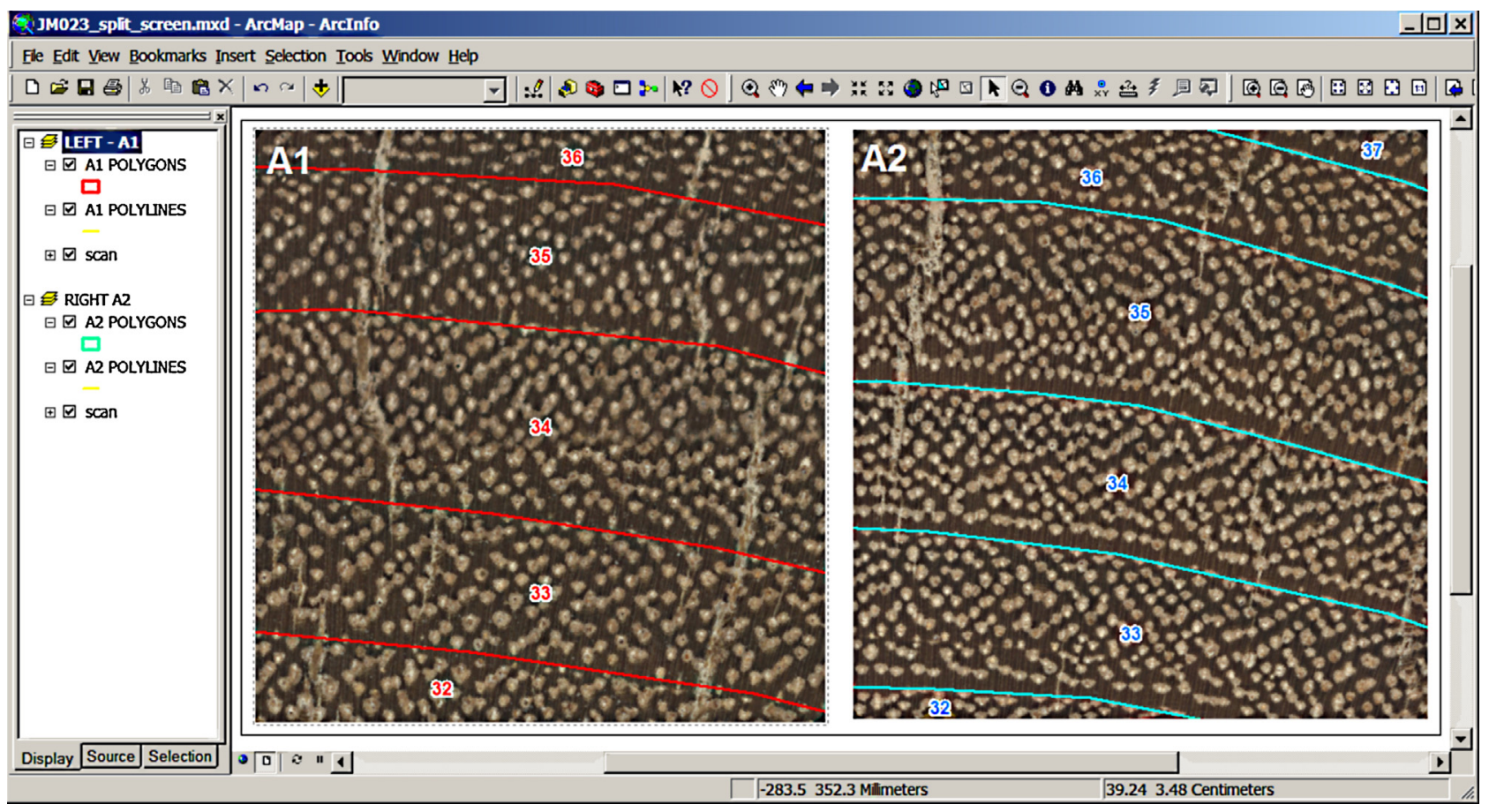

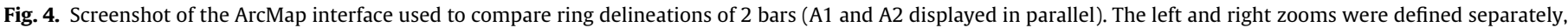
and are proportional to the pith-bark distance. Ring boundaries can be turned on/off with the check button on the left panel.

\section{Procedure outputs and requirements}

The main output of the procedure is the shrinkage-free image, which could be assimilated to a freshly sawed disk in terms of dimensions, but with a high-resolution sanded surface allowing for the observation of vessels and axial parenchyma. The use of control points enables precise and adaptive radial and tangential corrections, reversing the shrinkage fluctuations throughout the cross-section. A good image quality requires well-prepared wood samples in order to obtain a uniformly sanded flat surface; if not, the

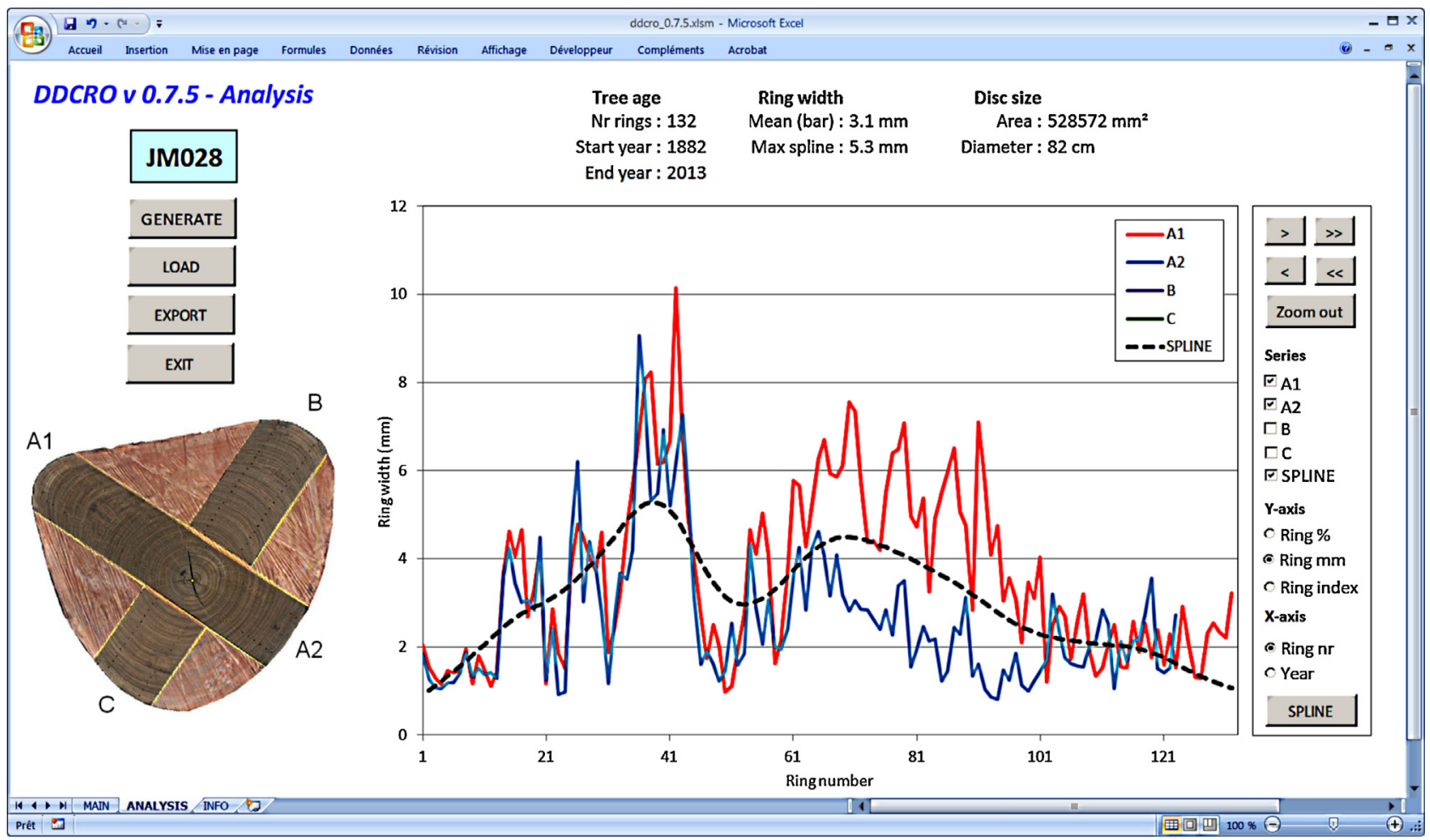

Fig. 5. Example of an interactive plot in Excel created by the application and used to compare the tree-ring series (which may or may not be detrended) of 2-4 bars of the same disk. 
use of the scanner auto-focus could, to some extent, limit undesirable blurry effects. Measurement data can be saved in the TUCSON format, which is compatible with most of the dendrochronological softwares useful for further treatment and analysis, such as Cofecha (Grissino-Mayer, 2001), Arstan (Cook, 1985), and the 'dplR' R package (Bunn, 2008).

The digital format offers new solutions for data management, as the storage on hard drives is safe and the price/capacity ratio has decreased substantially in the past several years. Research programs could take advantage of this to ensure decreased cost of disk transportation, handling, and storage. Wood sampling and photograph capture could be performed in the field, whereas the drying, sanding, and scanning procedures require adequate equipment and material. Therefore, wood samples are usually carried to a remote laboratory, although long distance transportation of cumbersome wood samples is a constraint, especially in the tropical forest. However, through long-term collaboration with the logging companies, e.g., in Cameroon (Fayolle et al., 2013, 2014; Ouédraogo et al., 2014), the sander, scanner, and computer could be used in a shelter located in the logging camp. Following laboratory work, image processing and tree-ring measurement, can be achieved anywhere, as data could easily be transferred online or on portable hard drives. Compared to the direct measurement on disk, the imagebased procedure presents another advantage: crossdating is less time-consuming due to easy update of series and data reprocessing.

The process implementation requires Excel, ArcGIS (ArcMap and ArcObjects), Photoscan, R, and MapWinGIS. The latter two are open-source applications. Excel is installed on most computers using the Windows operating system. ArcGIS (ArcInfo license) is indispensable for both versions of the procedure, whereas Photoscan (standard edition) is only used for shrinkage correction (in the complete procedure). The procedure requires computer intermediate skills specific to usage of the GIS environment and image processing softwares. The synergy created by the combination of several programs for specific parts in the task to be accomplished has already been highlighted by Hietz (2011).

Bars contain potentially less information compared to disks; however, bars are easier to handle (a disk $1 \mathrm{~m}$ in diameter with a thickness of $0.15 \mathrm{~m}$ weighs approximately $100 \mathrm{~kg}$, whereas 20$\mathrm{cm}$-wide bars weigh only $4 \times 12.5 \mathrm{~kg}$ ), the drying process is faster and offers good dimensional stability and a lower risk of cracking, and the better surface preparation improves the overall image quality. Furthermore, bar dimensions are suited for the use of small ovens and industrial sanders, which could save time. Bars are thus a good compromise between disks and cores. Disks and bars can be used separately or in a complementary fashion, depending on the difficulty of ring delineation and crossdating. For trees with very irregular stem forms (buttress roots), the use of disks is necessary. For poorly documented and unknown species, pioneering work on a limited number of disks should precede the work with bars. In our experience, series obtained using bars and disks are very similar, as the bar position is determined to be most representative of the disk, while avoiding the defects altering ring distinctiveness.

\section{Outlook}

The improvements in the procedure are still in process, in conjunction with our ongoing studies. Comparisons between the series of several trees should be drawn in order to limit the back-and-forth treatments required during pre-validation of the measurement data. The cross-dating process and the statistical analysis of chronology quality have not yet been implemented, but could be easily developed with use of R packages such as 'CrossdateR' (Bigler, 2005) and 'dplR' (Bunn, 2008). Furthermore, the application could be entirely transposed into an open-source framework by replacing ArcMap with Quantum GIS (http://www.qgis.org/) and ArcObjects with PostGIS (http://postgis.net/). The use of the control points to compare wood characteristics before and after the drying process could lead to new insight in shrinkage modeling relative to growth over time.

\section{Acknowledgement}

We thank the timber company Pallisco (www.pallisco-cifm. $\mathrm{com} /$ ) for allowing us to conduct wood sampling and providing facilities for field and laboratory work, and the NGO Nature+ for logistic support. We also thank Fousséni Fétéké and Coralie Mengal of the Forest Ressources Management unit (ULg - Gembloux AgroBio Tech) for their assistance during the procedure development (field data acquisition, image processing and application testing), and Adeline Fayolle for constructive comments.

\section{References}

Baier, T., Neuwirth, E., De Meo, M., 2011. Creating and deploying an application with (R) Excel and R. R J. 3/2, 5-11

Bär, A., Bräuning, A., Löffler, J., 2006. Dendroecology of dwarf shrubs in the high mountains of Norway - a methodological approach. Dendrochronologia 24 $17-27$.

Bigler, C., 2005. CrossdateR: A Visualization Tool to Assess the Quality of Crossdated Increment Cores. Institute of Terrestrial Ecosystems, ETH Zurich, 13 pp.

Bunn, A.G., 2008. A dendrochronology program library in R (dplR). Dendrochronologia 26 (2), 115-124

Cook, E.R., (Ph.D. Dissertation) 1985. A Time Series Analysis Approach to Tree-ring Standardization. University of Arizona.

ESRI, 2014. ArcGIS Desktop Help 9.3. http://webhelp.esri.com/arcgisdesktop/9.3 index.cfm? TopicName=Georeferencing_a_raster_dataset (accessed 25.03.14).

Fayolle, A., Doucet, J.L., Gillet, J.F., Bourland, N., Lejeune, P., 2013. Tree allometry in Central Africa: testing the validity of pantropical multi-species allometric equations for estimating biomass and carbon stocks. For. Ecol. Manag. 305, 29-37.

Fayolle, A., Picard, N., Doucet, J.L., Swaine, M., Bayol, N., Bénédet, F., Gourlet-Fleury, S., 2014. A new insight in the structure, composition, and functioning of Centra African moist forests. For. Ecol. Manag. 329, 195-205.

Gebrekirstos, A., Bräuning, A., Sass-Klassen, U., Mbow, C., 2014. Opportunities and applications of dendrochronology in Africa. Curr. Opin. Environ. Sustain. 6 (1), 48-53.

Grissino-Mayer, H.D., 2001. Evaluating crossdating accuracy: a manual and tutoria for the computer program COFECHA. Tree-Ring Res. 57 (2), 205-221.

Groenendijk, P., Sass-Klaassen, U., Bongers, F., Zuidema, P.A., 2014. Potential of treering analysis in a wet tropical forest: a case study on 22 commercial tree species in Central Africa. For. Ecol. Manag. 323, 65-68.

Hietz, P., 2011. A simple program to measure and analyse tree rings using Excel, R, and SigmaScan. Dendrochronologia 29, 245-250.

Ouédraogo, D.Y., Fayolle, A., Daïnou, K., Demaret, C., Bourland, N., Lagoute, P., Doucet J.L., 2014. Enrichment of logging gaps with a high conservation value species (Pericopsis elata) in a central African moist forest. Forests 5, 3031-3047.

Kukachka, B.F., 1970. Properties of imported tropical woods. US Forest Service Research Paper, FPL 125.

R Core Team, 2014. R: A Language and Environment for Statistical Computing. R Foundation for Statistical Computing, Vienna, Austria http://www.R-project. org/

Rozendaal, D.M.A., Zuidema, P.A., 2011. Dendroecology in the tropics: a review. Trees - Struct. Funct. 25 (1), 3-16.

Wagenführ, R. (Ed.), 1996. Holzatlas. Carl Hanser Verlag, Leipzig, 385 pp.

Worbes, M., 2002. One hundred years of tree-ring research in the tropics - a brief history and an outlook to future challenges. Dendrochronologia 20 (1-2) 217-231 